\title{
OPEN Symptoms and pathogens diversity of Corn Fusarium sheath rot in Sichuan Province, China
}

\author{
Wei Wang ${ }^{1}$, Bo Wang ${ }^{1}$, Xiaofang Sun ${ }^{1}$, Xiaobo $\mathrm{Qi}^{1}$, Conghao Zhao ${ }^{1}$, Xiaoli Chang ${ }^{1}$, \\ Muhammad Ibrahim Khaskheli ${ }^{2}$ \& Guoshu Gong ${ }^{1 凶}$
}

To elucidate the symptoms and pathogens diversity of corn Fusarium sheath rot (CFSR), diseased samples were collected from 21 county-level regions in 12 prefecture-level districts of Sichuan Province from 2015 to 2018 in the present study. In the field, two symptom types appeared including small black spots with a linear distribution and wet blotches with a tawny or brown color. One hundred thirty-seven Fusarium isolates were identified based on morphological characteristics and phylogenetic analysis (EF1- $\alpha$ ), and Koch's postulates were also assessed. The results identified the isolates as 8 species in the Fusarium genus, including F. verticillioides, F. proliferatum, F. fujikuroi, $F$. asiaticum, F. equiseti, F. meridionale, F. graminearum and $F$. oxysporum, with isolation frequencies of $30.00,22.67,15.33,7.33,6.00,5.33,3.33$ and $1.33 \%$, respectively. Fusarium verticillioides and $F$. proliferatum were the dominant and subdominant species, respectively. Two or more Fusarium species such as $F$. verticillioides and $F$. proliferatum were simultaneously identified at a mixed infection rate of $14.67 \%$ in the present study. The pathogenicity test results showed that $F$. proliferatum and $F$. fujikuroi exhibited the highest virulence, with average disease indices of $30.28 \pm 2.87$ and $28.06 \pm 1.96$, followed by $F$. equiseti and $F$. verticillioides, with disease indices of $21.48 \pm 2.14$ and $16.21 \pm 1.84$, respectively. Fusarium asiaticum, F. graminearum and $F$. meridonale showed lower virulence, with disease indices of $13.80 \pm 2.07,11.57 \pm 2.40$ and $13.89 \pm 2.49$, respectively. Finally, F. orysporum presented the lowest virulence in CFSR, with a disease index of $10.14 \pm 1.20$. To the best of our knowledge, this is the first report of F. fujikuroi, F. meridionale and F. asiaticum as CFSR pathogens in China.

Maize (Zea mays L.) is one of the largest food staples worldwide and is one of the most economically important crops in China ${ }^{1}$. Maize yields as high as 260.77 billion kilograms have been attained in China, greatly contributing to ensuring food safety and increasing farmer income ${ }^{2-4}$. In China, the maize-sowing area reached approximately 44.96 million $\mathrm{hm}^{2}$ in 2015 , after which it decreased to 42.39 million $\mathrm{hm}^{2}$ in $2017^{5}$. Chinese maize production of 259 million tons has been reported, accounting for $39 \%$ of Chinese cereal crop production and $22.8 \%$ of the global maize output ${ }^{6}$. However, several diseases caused by fungi, bacteria and viruses are a major factor limiting maize production. Among these diseases, Fusarium spp. can cause ear rot, stalk rot, seedling blight and root rot ${ }^{7}$.

Corn Fusarium sheath rot (CFSR) is one of the most serious crop diseases in China ${ }^{8,9}$. The results of previous studies suggest that Fusarium proliferatum can not only affect maize production but also produces the toxin fumonisins, posing great risks to human and livestock ${ }^{10}$. F. graminearum, F. verticillioides and $F$. equiseti have also been identified as causal agents of $\mathrm{CFSR}^{8,11}$. In fields, these pathogens primarily infect the sheath from the late growth period to the grain-forming stage $\mathrm{e}^{11}$. Initial symptoms appear as irregular circular brown necrotic spots, after which the entire sheath gradually appears water-soaked and finally dies ${ }^{12,13}$. A severely infected sheath can eventually reduce lodging resistance and yield. According to statistical data, lodging results in major economic losses of approximately $15-25 \%$ and can even result in total crop failure ${ }^{14}$. A positive correlation has been demonstrated between yield loss and disease severity ${ }^{15}$. Additionally, wounds caused by aphid feeding can exacerbate the sheath rot severity of maize ${ }^{16}$.

Studies have shown that CFSR has occurred in more than 12 provinces in China ${ }^{17}$. However, the disease has not been reported in Sichuan Province, a major maize-producing region in China. Therefore, the goal of our present study was to characterize the disease severity, symptoms and Fusarium spp. pathogens of CFSR, which will provide an important basis for effective integrated control of this disease.

${ }^{1}$ College of Agronomy, Sichuan Agricultural University, Chengdu 611130, China. ${ }^{2}$ Department of Plant Protection, Faculty of Crop Protection, Sindh Agriculture University, Tandojam 70060, Pakistan. ${ }^{\square}$ email: guoshugong@126.com 

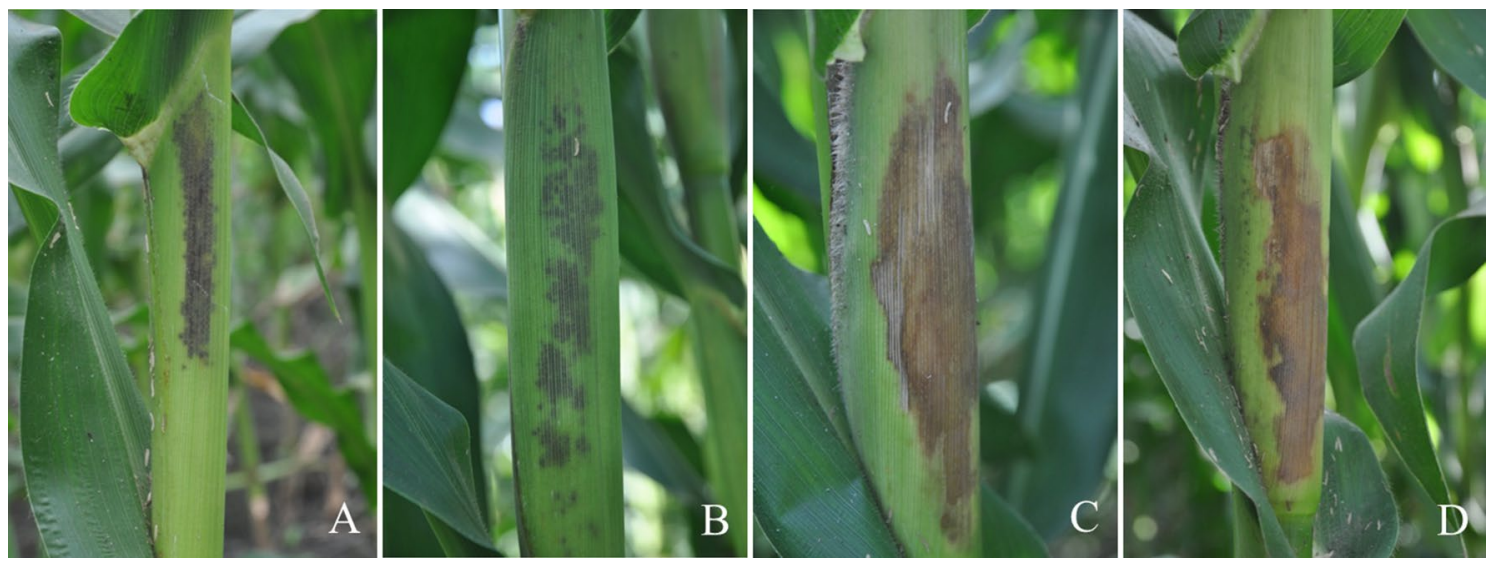

Figure 1. Disease symptoms of corn Fusarium sheath rot in the field were divided into two types of symptoms: small black spots with a linear distribution $(\mathbf{A}, \mathbf{B})$ and wet blotches with a tawny or brown color $(\mathbf{C}, \mathbf{D})$.
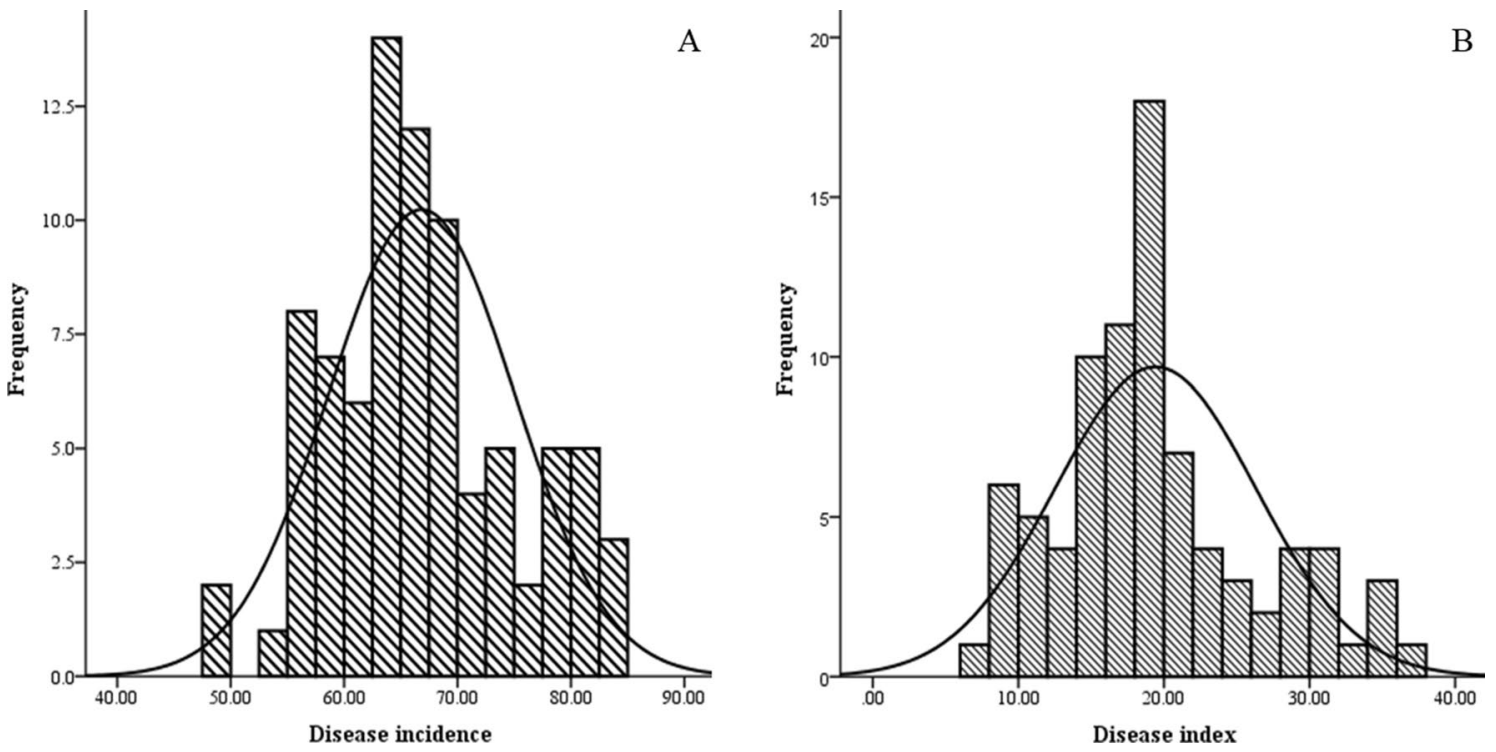

Figure 2. Statistics of disease incidence (A) and the disease index (B) of corn Fusarium sheath rot at 84 investigated sites in Sichuan Province, China.

\begin{tabular}{|l|l|l|l|l|l|l|l|l|l|l|l|}
\hline & \multirow{3}{*}{} & & & & \multicolumn{2}{l|}{ Average } & \multicolumn{2}{l|}{ Skewness } & \multicolumn{2}{l|}{ Kurtosis } \\
\cline { 7 - 12 } & N & Minimum & Maximum & Standard deviation & Statistic & SE & Statistic & SE & Statistic & SE \\
\hline Disease index & 84 & 7.32 & 37.62 & 6.92 & 19.42 & 0.75 & 0.62 & 0.26 & 0.004 & 0.52 \\
\hline Disease incidence & 84 & $49.59 \%$ & $84.18 \%$ & $8.19 \%$ & $66.83 \%$ & $0.89 \%$ & 0.29 & 0.26 & -0.43 & 0.52 \\
\hline
\end{tabular}

Table 1. Statistical description of the disease incidence and disease index values based on the investigation of corn Fusarium sheath rot in the field.

\section{Results}

Occurrence of corn Fusarium sheath rot (CFSR) in the field. In the present study, we investigated the occurrence of CFSR from 2015 to 2018. CFSR is characterized by two primary types of disease symptoms in the field (Fig. 1), including small black spots with a linear distribution (Fig. 1A,B) and wet blotches with a tawny or brown color (Fig. 1C,D). Disease incidence primarily ranged from 55 to $70 \%$ (Fig. 2A), and the disease index primarily ranged from 14.00 to 22.00 for CFSR (Fig. 2B). Among 84 investigated spots, the disease incidence ranged from $49.59-84.16 \%$, with an average of $66.83 \pm 0.89 \%$, while the disease index ranged from 7.32 to 37.62 , with an average of $19.42 \pm 0.75$ (Table 1). 


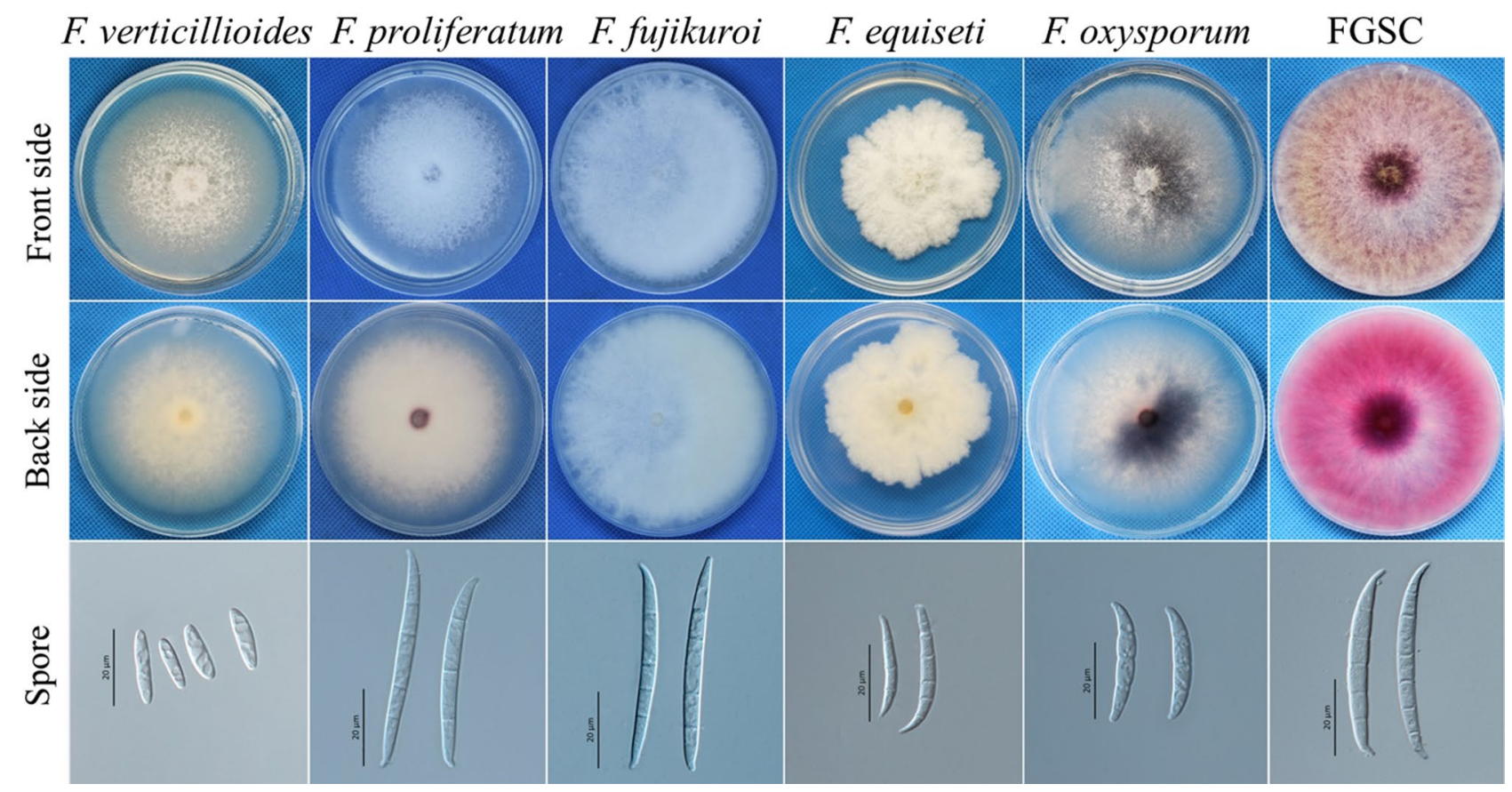

Figure 3. Representative colonies formed on PDA and conidial morphology characteristics.

\begin{tabular}{|c|c|c|c|c|c|c|c|}
\hline \multirow[b]{2}{*}{ Groups } & \multirow{2}{*}{$\begin{array}{l}\text { Colonies } \\
\text { appearance }\end{array}$} & \multirow{2}{*}{$\begin{array}{l}\text { Growth rate }(\mathrm{mm} / \\
\text { day) }\end{array}$} & \multicolumn{5}{|l|}{ Conidia } \\
\hline & & & Length $(\mu \mathrm{m})$ & Width $(\mu \mathrm{m})$ & Septum & Shape & Foot spore \\
\hline F. verticillioides & $\begin{array}{l}\text { White mycelia } \\
\text { and light yellow } \\
\text { regularly colony }\end{array}$ & $4.76 \pm 0.57 b$ & $23.58 \pm 2.81 \mathrm{e}$ & $3.74 \pm 0.20 \mathrm{bc}$ & $3-4$ & Fusiform & + \\
\hline F. proliferatum & $\begin{array}{l}\text { White mycelia and } \\
\text { purple regularly } \\
\text { colony }\end{array}$ & $6.47 \pm 0.62 \mathrm{a}$ & $45.72 \pm 5.14 \mathrm{c}$ & $3.55 \pm 0.27 \mathrm{c}$ & $3-4$ & Fusiform, Falcate & + \\
\hline F. fujikuroi & $\begin{array}{l}\text { White mycelia and } \\
\text { offwhite regularly } \\
\text { colony }\end{array}$ & $6.43 \pm 0.60 \mathrm{a}$ & $52.17 \pm 2.13 \mathrm{ab}$ & $4.09 \pm 0.19 \mathrm{~b}$ & $3-5$ & Falcate & + \\
\hline F. equiseti & $\begin{array}{l}\text { White mycelia } \\
\text { and light yellow } \\
\text { unregularly colony }\end{array}$ & $4.92 \pm 0.56 \mathrm{~b}$ & $18.34 \pm 2.94 \mathrm{f}$ & $4.14 \pm 0.95 b$ & $2-3$ & Matt, Falcate & - \\
\hline F. oxysporum & $\begin{array}{l}\text { White mycelia and } \\
\text { modena regularly } \\
\text { colony }\end{array}$ & $5.03 \pm 1.14 \mathrm{~b}$ & $28.43 \pm 4.29 \mathrm{~d}$ & $4.08 \pm 0.67 \mathrm{~b}$ & $2-3$ & Falcate & + \\
\hline FGSC & $\begin{array}{l}\text { White and yellow } \\
\text { mycelia and red } \\
\text { regularly colony }\end{array}$ & $6.64 \pm 0.42 \mathrm{a}$ & $50.98 \pm 6.45 b$ & $4.96 \pm 0.34 \mathrm{a}$ & $4-6$ & Falciform & + \\
\hline
\end{tabular}

Table 2. The morphological characteristics of Fusarium species were observed on PDA for 3 days at approximately $25^{\circ} \mathrm{C}$ under $12 \mathrm{~h}$ of light per day. Different lowercase letters indicate a significant difference at the 5\% level by Duncan's least significant range test. FGSC: Fusarium graminearum species complex.

Identification of Fusarium species associated with CFSR. One hundred thirty-seven Fusarium isolates from 150 maize sheath samples were divided into six types according to the color and shape of their colonies and the morphology of their conidia (Fig. 3). The features of the macroconidia are described in Table 2. For further molecular verification, partial $r D N A$-ITS gene sequences were amplified, generating a 560-bp band, and analyses of sequence similarity showed that 137 Fusarium isolates exhibited greater than $95-99 \%$ similarity with sequences from the F. graminearum species complex (FGSC), F. fujikuroi species complex (FFSC), F. incarnatum-equiseti species complex (FIESC), F. oxysporum and F. verticillioides in the databases of NCBI (http://www. ncbi.nlm.nih.gov) and the FUSARIUM-ID (http://isolate.fusariumdb.org/guide.php).

In addition, a partial EF- $1 \alpha$ gene sequence was amplified, generating a 700-bp band. For further phylogenetic analysis, a neighbor-joining tree based on the EF-1 $\alpha$ gene was constructed, which included 137 Fusarium isolates, 17 reference isolates and 1 outgroup isolate of Bipolaris oryzae (B33, KJ 939510) (See Supplementary Table S1 online). As shown in Fig. 4, all isolates were clearly classified into eight species, including F. vertieillioides, $F$. proliferatum, F. fujikuroi, F. asiaticum, F. equiseti, F. meridonale, F. graminearum and F. orysporum. 


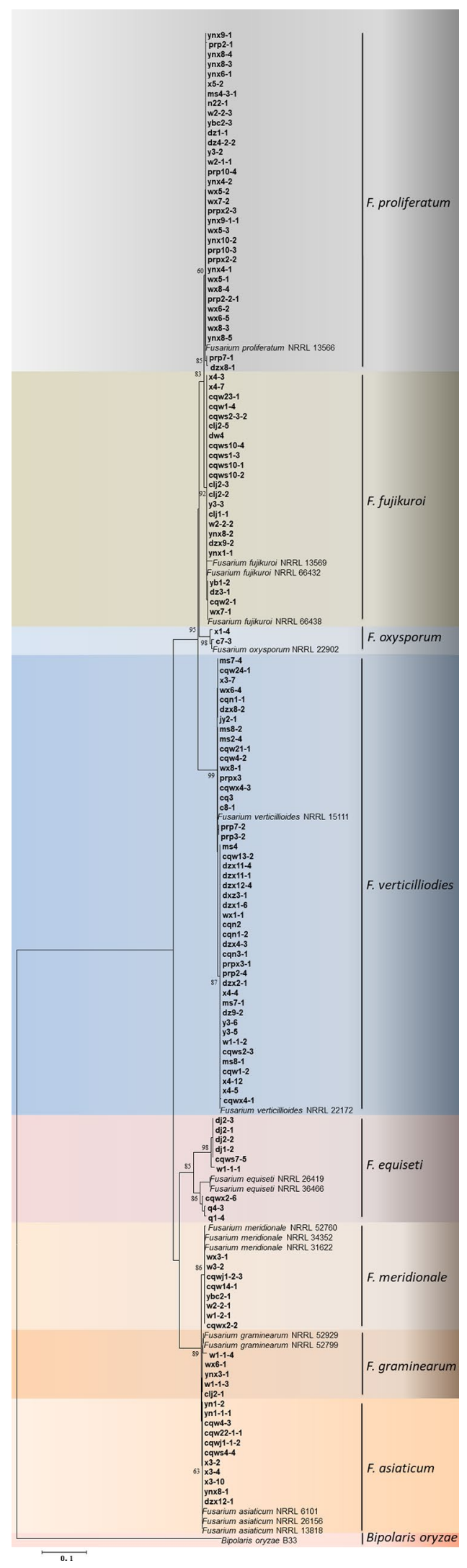

Figure 4. Phylogenetic tree of Fusarium isolates based on neighbor-joining analysis of the EF1- $\alpha$ gene; bootstrap values are from a bootstrap test of 1000 replicates. Isolates for which type strains were included in the study are indicated in boldface. 


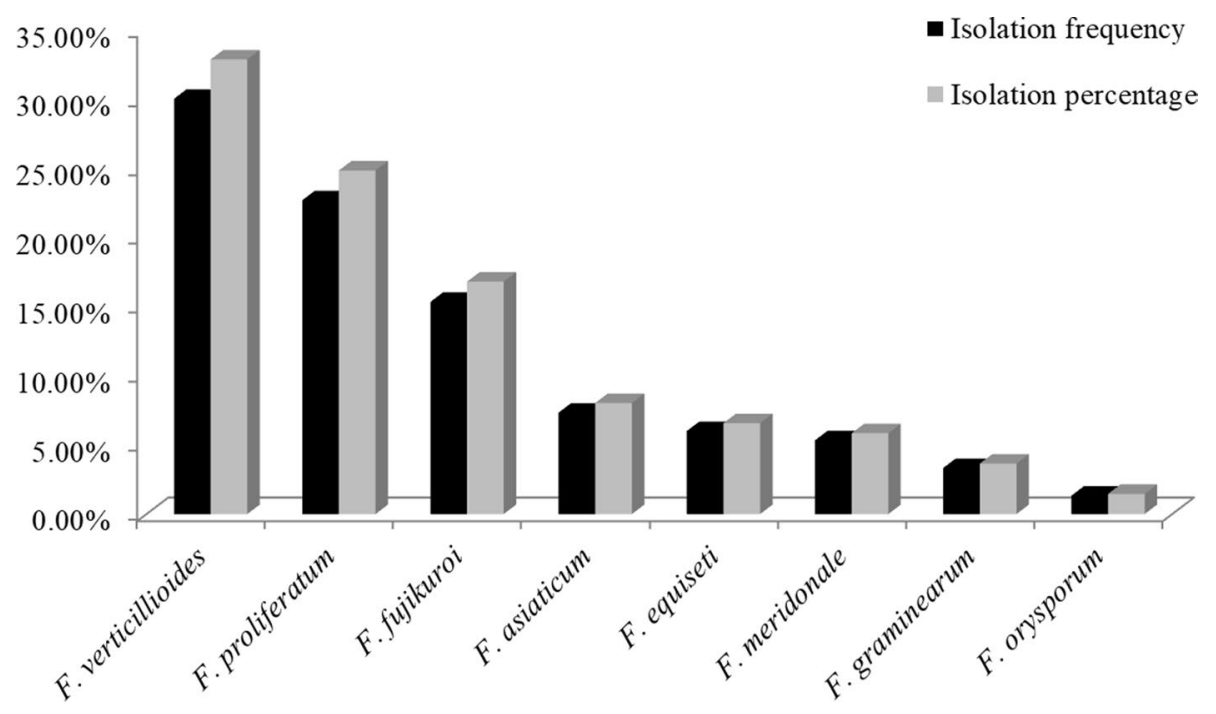

Figure 5. Isolation frequency of Fusarium species from maize sheaths in Sichuan Province, China.

CK F. proliferatum F. fujikuroi F. equiseti F. verticillioides F. meridionale F. asiaticum F. graminearum F. oxysporum
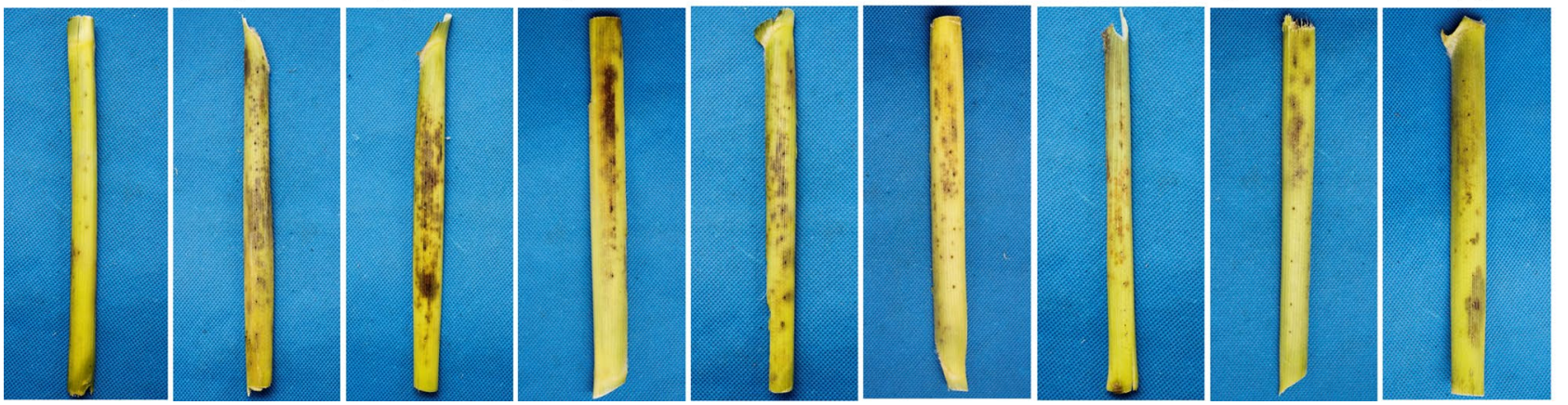

Figure 6. Inoculation of maize sheaths with different Fusarium spp. isolates (the maize cultivar is Chuandan 428).

Isolation frequency of eight Fusarium species. In the present study, F. verticillioides and F. proliferatum were always observed in mixed infections on maize sheaths. Two or more Fusarium species were simultaneously identified from each of 22 sheath samples with a mixed infection rate $14.67 \%$, and the frequencies at which Fusarium species were isolated are shown in Fig. 5 and Table S2. The isolation frequencies of $F$. verticillioides, $F$. proliferatum, F. fujikuroi, F. asiaticum, F. equiseti, F. meridionale, F. graminearum and F. oxysporum were 30.00, $22.67,15.33,7.33,6.00,5.33,3.33$ and $1.33 \%$, respectively. Additionally, a comparison of the percentages of isolates obtained for the eight Fusarium species revealed that $F$. verticillioides accounted for $32.84 \%$ of all Fusarium isolates, followed by $24.82 \%$ for F. proliferatum, $16.79 \%$ for F. fujikuroi, $8.03 \%$ for F. asiaticum, $6.57 \%$ for F. equiseti and $5.84 \%$ for F. meridonale, while F. graminearum and F. orysporum accounted for 3.65 and $1.46 \%$ of the isolates, respectively.

Pathogenicity test of Fusarium species. To assess the pathogenicity of the Fusarium species identified from the maize sheaths in Sichuan Province, symptoms of CFSR were observed at 25 days after inoculation with twenty-three representative Fusarium isolates from eight Fusarium species (Table 2), and the disease index was calculated according to disease severity caused by Fusarium species. Four maize cultivars were tested here. The symptoms of small black spots with a homogeneous distribution (caused by F. proliferatum, F. fujikuroi, F. equiseti, F. verticillioides, F. meridonale, F. asiaticum and F. graminearum) and wet blotches with a tawny color (caused by F. orysporum) were observed after inoculation, while the control plants showed no significant symptoms (Fig. 6).

All Fusarium isolates were pathogenic and caused CFSR, with disease indices ranging from 10.14-30.28. Among the assayed isolates, F. proliferatum and F. fujikuroi showed significantly higher virulence than the other Fusarium species $(\mathrm{P}<0.05)$, with average disease indices of $30.28 \pm 2.87$ and $28.06 \pm 1.96$ (Table 3$)$, followed by $F$. equiseti and $F$. verticillioides, which had similar disease indices of $21.48 \pm 2.14$ and $16.21 \pm 1.84$, respectively. $F$. asiaticum, F. graminearum and F. meridonale, members of the FGSC, also caused CFSR following inoculation but 


\begin{tabular}{|c|c|c|c|c|c|c|}
\hline Fusarium spp. & Isolate ID & Chuandan 455 & Zhenghong 6 & Chuandan 428 & Ruiyu 16 & Average \\
\hline \multirow{3}{*}{ F. proliferatum } & ynx8-3 & $34.44 \pm 2.35 \mathrm{ab}$ & $30.00 \pm 2.62 \mathrm{a}$ & $30.00 \pm 1.44 \mathrm{a}$ & $26.67 \pm 1.91 \mathrm{ab}$ & \multirow{3}{*}{$30.28 \pm 0.23 \mathrm{a}$} \\
\hline & wx5-2 & $32.22 \pm 2.91 \mathrm{bc}$ & $32.22 \pm 1.36 \mathrm{a}$ & $28.89 \pm 2.26 \mathrm{ab}$ & $28.89 \pm 1.09 \mathrm{ab}$ & \\
\hline & dz1-1 & $37.78 \pm 2.72 \mathrm{a}$ & $28.89 \pm 2.18 \mathrm{ab}$ & $27.78 \pm 2.17 \mathrm{ab}$ & $25.56 \pm 0.48 \mathrm{~b}$ & \\
\hline \multirow{3}{*}{ F. fujikuroi } & $\times 4-3$ & $30.00 \pm 2.89 \mathrm{cde}$ & $28.89 \pm 2.25 \mathrm{ab}$ & $25.56 \pm 1.71 \mathrm{~b}$ & $28.89 \pm 3.27 \mathrm{ab}$ & \multirow{3}{*}{$26.14 \pm 2.58 \mathrm{~b}$} \\
\hline & cqw2-1 & $27.78 \pm 0.96 \mathrm{def}$ & $30.00 \pm 3.53 \mathrm{a}$ & $26.67 \pm 2.27 \mathrm{ab}$ & $30.00 \pm 1.04 \mathrm{a}$ & \\
\hline & w2-2-2 & $31.11 \pm 3.00 \mathrm{bcd}$ & $25.56 \pm 3.25 \mathrm{~b}$ & $22.22 \pm 3.45 c$ & $30.00 \pm 2.20 \mathrm{a}$ & \\
\hline \multirow{3}{*}{ F. equiseti } & dj2-2 & $25.56 \pm 1.61 \mathrm{fg}$ & $21.11 \pm 0.75 c$ & $21.11 \pm 1.20 \mathrm{c}$ & $18.89 \pm 1.09 \mathrm{~d}$ & \multirow{3}{*}{$21.48 \pm 1.14 \mathrm{c}$} \\
\hline & \begin{tabular}{|l|} 
w1-1-1 \\
\end{tabular} & $22.22 \pm 0.56 \mathrm{gh}$ & $18.89 \pm 1.02 \mathrm{~cd}$ & $22.22 \pm 1.20 c$ & $16.67 \pm 1.65 \mathrm{de}$ & \\
\hline & cqws7-5 & $26.67 \pm 0.65 \mathrm{ef}$ & $25.56 \pm 1.56 \mathrm{~b}$ & $16.67 \pm 2.42 \mathrm{~d}$ & $22.22 \pm 1.90 \mathrm{c}$ & \\
\hline \multirow{3}{*}{ F. verticillioides } & cqw4-2 & \begin{tabular}{|l|}
$16.67 \pm 1.53 \mathrm{ijk}$ \\
\end{tabular} & $18.89 \pm 1.12 \mathrm{~cd}$ & $13.33 \pm 1.47 \mathrm{defg}$ & $18.89 \pm 2.61 \mathrm{~d}$ & \multirow{3}{*}{$16.20 \pm 0.57 \mathrm{~d}$} \\
\hline & $\times 4-5$ & $18.89 \pm 1.09 \mathrm{hi}$ & $15.56 \pm 1.65 \mathrm{def}$ & $14.44 \pm 1.43 \mathrm{def}$ & $15.56 \pm 0.72 \mathrm{def}$ & \\
\hline & ms7-1 & $22.22 \pm 0.78 \mathrm{gh}$ & $13.33 \pm 2.42 \mathrm{efg}$ & $15.56 \pm 1.40 \mathrm{de}$ & $11.11 \pm 0.37 \mathrm{ghi}$ & \\
\hline \multirow{3}{*}{ F. meridionale } & w2-2-1 & $15.56 \pm 1.62 \mathrm{ijk}$ & $15.56 \pm 1.40 \mathrm{def}$ & $8.89 \pm 0.73 \mathrm{hi}$ & $16.67 \pm 1.70 \mathrm{de}$ & \multirow{3}{*}{$14.07 \pm 0.35 \mathrm{de}$} \\
\hline & \begin{tabular}{|l|} 
cqw14-1 \\
\end{tabular} & $17.78 \pm 0.73 \mathrm{ij}$ & $14.44 \pm 1.44 \mathrm{efg}$ & $11.11 \pm 1.20$ fghi & $14.44 \pm 1.44 \mathrm{efg}$ & \\
\hline & w3-2 & $18.89 \pm 1.10 \mathrm{hi}$ & $13.33 \pm 0.53 \mathrm{efg}$ & $11.11 \pm 0.43$ fghi & $11.11 \pm 0.67 \mathrm{ghi}$ & \\
\hline \multirow{3}{*}{ F. asiaticum } & cqw4-3 & $17.78 \pm 1.54 \mathrm{ij}$ & $16.67 \pm 1.71 \mathrm{de}$ & $12.22 \pm 0.92 \mathrm{efgh}$ & $13.33 \pm 1.50$ efgh & \multirow{3}{*}{$13.80 \pm 1.02 \mathrm{de}$} \\
\hline & cqws4-4 & $16.67 \pm 2.56 \mathrm{ijk}$ & $15.56 \pm 1.54 \mathrm{def}$ & $12.22 \pm 1.32 \mathrm{efgh}$ & $11.11 \pm 1.11 \mathrm{ghi}$ & \\
\hline & yn1-2 & $15.56 \pm 1.04 \mathrm{ijk}$ & $12.22 \pm 0.78 \mathrm{fgh}$ & $10.00 \pm 0.80 \mathrm{ghi}$ & $12.22 \pm 1.44$ fghi & \\
\hline \multirow{3}{*}{ F. graminearum } & w1-1-4 & $16.67 \pm 1.15 \mathrm{ijk}$ & $13.33 \pm 0.93 \mathrm{efg}$ & $7.78 \pm 0.43 \mathrm{i}$ & $11.11 \pm 1.49 \mathrm{ghi}$ & \multirow{3}{*}{$11.57 \pm 0.57$ ef } \\
\hline & clj2-1 & $14.44 \pm 1.06 \mathrm{jk}$ & $12.22 \pm 1.09 \mathrm{fgh}$ & $10.00 \pm 0.65 \mathrm{ghi}$ & $10.00 \pm 1.43 \mathrm{hi}$ & \\
\hline & wx6-1 & $14.44 \pm 1.91 \mathrm{jk}$ & $11.11 \pm 0.20 \mathrm{gh}$ & $8.89 \pm 1.37 \mathrm{hi}$ & $8.89 \pm 1.18 \mathrm{i}$ & \\
\hline \multirow{2}{*}{ F. oxysporum } & $\times 1-4$ & $13.33 \pm 0.61 \mathrm{kl}$ & $11.11 \pm 1.19 \mathrm{gh}$ & $7.78 \pm 0.63 \mathrm{i}$ & $12.22 \pm 0.79$ fghi & \multirow{2}{*}{$10.14 \pm 0.97 \mathrm{f}$} \\
\hline & c7-3 & $10.01 \pm 1.081$ & $8.89 \pm 0.82 \mathrm{~h}$ & $8.90 \pm 0.88 \mathrm{hi}$ & $8.90 \pm 1.18 \mathrm{i}$ & \\
\hline
\end{tabular}

Table 3. The disease index values for maize sheaths inoculated with Fusarium spp. in different maize cultivars. Different lowercase in the same column shows a significant difference at the level of $\mathrm{p}=0.05$, according to Duncan's least significant range test.

with somewhat lower virulence, with disease indices ranging from 11.57-13.89. F. orysporum showed the lowest virulence, causing CFSR with a disease index of $10.14 \pm 1.20$. For this species, there were no sheath rot symptoms and only a few signs of mechanical damage on the noninoculated maize sheath (Fig. 6). Finally, the pathogens were reisolated and identified, applying Koch's postulates to determine their pathogenicity. Our results demonstrated that the disease symptoms of wet blotches with a tawny or brown color were caused by F. orysporum, whereas small black spots were caused by F. verticillioides, F. proliferatum, F. equiseti, F. asiaticum, F. graminearum and F. meridonale. This is the first report of F. fujikuroi, F. meridionale and F. asiaticum causing CFSR in China.

\section{Discussion}

Many studies have demonstrated that various Fusarium species, such as pathogens isolated in Henan, Hebei, Shandong and Gansu are associated with CFSR, which has significantly affected the quality and quantity of maize since it was first reported in northeast China in $2008^{11,18}$. In the present survey, the occurrence of CFSR was commonly observed, with two primary types of disease symptoms detected in the field (Fig. 1), including small black spots with a linear distribution and wet blotches with a tawny or brown color, similar to that described by Zhai ${ }^{11}$. Based on a survey conducted from 2015 to 2018, the disease incidence was very high, at $49.59-84.18 \%$, with an average of $66.83 \%$, and the severity of the disease index ranged from 7.32 to 37.62 , with an average of 19.43 in the Sichuan fields.

Previous studies demonstrated that a complex of five Fusarium species, including F. proliferatum, F. verticillioides, F. equiseti, F. graminearum and F. orysporum, cause CFSR ${ }^{11,19,20}$. In the present study, we identified eight Fusarium species based on morphological characteristics and phylogenetic analysis (EF1- $\alpha$ ), including $F$. verticillioides, F. proliferatum, F. fujikuroi, F. asiaticum, F. equiseti, F. meridionale, F. graminearum and F. oxysporum, with observed isolation frequencies of $30.00,22.67,15.33,7.33,6.00,5.33,3.33$ and 1.33\%, respectively. Many studies have shown that Fusarium species are consistently isolated and identified in mixed infections with other Fusarium species or fungi on many crops in the field ${ }^{21,22}$. In the present study, F. verticillioides and $F$. proliferatum were consistently observed in mixed infections in CFSR on maize, with a mixed infection rate of $14.67 \%$.

Fusarium proliferatum is a ubiquitous, polyphagous, highly adaptable fungal pathogen of different plant species that attacks plants both in the field and during postharvest storage, causing blights, rots, and wilts on maize, garlic, soybean, tomato and Aloe vera ${ }^{7,19,23-26}$. Interestingly, several studies have shown that $F$. proliferatum is also the predominant pathogen of some commercial crops, such as Polygonatum cyrtonema, date palm and Cymbidium $^{27-29}$. F. proliferatum was observed as the dominant fungus in infected garlic bulbs, with a high disease incidence of $35.40 \%$, and it was confirmed as the causal agent of dry rot in garlic postharvest ${ }^{30}$. F. proliferatum was also highly pathogenic, and significant symptoms were also observed 2 weeks after being inoculated on onion ${ }^{31}$. On soybean, F. proliferatum easily infected seeds, with an observed disease severity index of $43.33-49.16 \%{ }^{32}$. In 
our present study, F. proliferatum exhibited the highest virulence among the evaluated species, with a disease index of 30.28 in four different maize varieties, which is consistent with results of previous studies ${ }^{8,16}$. Additionally, F. proliferatum was also widely distributed, with an isolation frequency of $24.82 \%$. F. equiseti, F. verticillioides and F. graminearum were successively reported as pathogens in $\mathrm{CFSR}^{11,33}$. Interestingly, F. fujikuroi, F. meridionale and F. asiaticum species were recorded as causing CFSR for the first time in China in the present study (Fig. 4).

Several studies have shown that $F$. fujikuroi causes rice bakanae disease and ear and stalk rot in maize ${ }^{34,35}$. In our present study, F. fujikuroi was the primary pathogen of CFSR, and F. verticillioides and F. proliferatum also exhibited strong pathogenicity, with an isolation frequency of $16.79 \%$ and a disease index of 28.06 . F. graminearum is perhaps the best-known pathogen for causing head blight in wheat and ear and stalk rot in maize $\mathrm{e}^{36,37}$. F. graminearum was detected in $\geq 80 \%$ of all Fusarium head blight (FHB) samples, sometimes even $100 \%{ }^{38}$. In addition, the frequency of $F$ graminearum isolated from ears ranged from 30 to $71 \%$ with an average of $57 \%$, and from stalks ranged from 43 to $81 \%$, with the average of $65 \%{ }^{39}$. Although the isolation frequency of F. graminearum from CFSR was only $3.65 \%$ in our present study, the potential risk of mycotoxins produced by F. graminearum to human health cannot be ignored ${ }^{40}$.

Fusarium meridonale is a member of the FGSC that is well-known to cause FHB in wheat and barley worldwide ${ }^{41}$. In addition, F. meridionale was also recently reported as pathogen in root rot on soybean under monoculture and ear rot on maize ${ }^{42,43}$. Moreover, F. asiaticum has been reported as a major and dominant causal agent of FHB on wheat and barley in China ${ }^{44-46}$ and was also detected as a pathogen causing Gibberella ear rot of maize and seedborne diseases of soybean ${ }^{47,48}$. Although F. meridonale and F. asiaticum were not predominant species in the present study, with low isolation frequencies, they were reported in China for the first time. On the other hand, F. meridonale and F. asiaticum also exhibited typical pathogenicity, with disease indices of 13.89 and 13.80 , respectively.

In summary, in the present study, eight species of Fusarium were recovered from maize fields in Sichuan Province, China. Interestingly, three species, F. fujikuroi, F. meridionale and F. asiaticum, were reported to cause CFSR in China for the first time. All isolates could infect the maize sheath and had disease indices ranging from 10.14 to 30.28 . F. proliferatum and F. fujikuroi were the primary pathogens of CFSR, exhibiting high isolation frequencies and disease indices. The results of the present study provides the theoretical basis for integrated control of CFSR in Sichuan Province of China.

\section{Methods}

Survey and sampling. Twenty-one county-level regions of 12 municipal administrations were surveyed for sampling between 2015 and 2018 in Sichuan, China. The disease percentage and severity of CFSR under natural conditions were investigated as described by Huang et al. ${ }^{49}$. Four fields that were at least $1 \mathrm{~km}$ apart were contained in each area, and five sites were evaluated in each field, with 100 ear leaf sheaths sampled per site. In addition, 150 diseased maize sheaths with dark brown spots or bronzing and tawny blotch were collected in valve bags and stored in a large ice box before cultural isolation.

Isolated and morphological observations of Fusarium spp.. The pathogens were isolated from maize sheaths by tissue and single spore isolation ${ }^{50,51}$. Maize sheaths were cut into $0.5 \mathrm{~cm} \times 0.5 \mathrm{~cm}$ pieces at the junction between disease and healthy tissue prior to isolation. The sheaths were surface-sterilized in $1 \%$ sodium hypochlorite for $1 \mathrm{~min}$, rinsed extensively with sterilized water, soaked in $75 \%$ ethanol for $30 \mathrm{~s}$, and then rinsed extensively with sterilized water again. Subsequently, all sample pieces were placed on potato dextrose agar (PDA; $200 \mathrm{~g} \cdot \mathrm{L}^{-1}$ potato, $10 \mathrm{~g} \cdot \mathrm{L}^{-1}$ glucose anhydrous, and $15 \mathrm{~g} \cdot \mathrm{L}^{-1}$ agar) plates supplemented with $0.2 \mathrm{~g}$ chloramphenicol for fungal isolation for 3 days at approximately $25^{\circ} \mathrm{C}$ under 12 -h lighting.

Additionally, all strains were transferred to liquid carboxymethyl cellulose medium (CMC; $7.5 \mathrm{~g} \cdot \mathrm{L}^{-1}$ carboxymethyl cellulose sodium, $0.5 \mathrm{~g} \cdot \mathrm{L}^{-1}$ yeast extract, $2.5 \mathrm{~g} \cdot \mathrm{L}^{-1} \mathrm{~K}_{2} \mathrm{HPO}_{4}$, and $\left.0.25 \mathrm{~g} \cdot \mathrm{L}^{-1} \mathrm{MgSO}_{4} \cdot 7 \mathrm{H}_{2} \mathrm{O}\right)^{52}$. Then, the inoculated cultures were incubated for 5 days in a shaking incubator at $27^{\circ} \mathrm{C}, 120 \mathrm{rpm}$. The culture characteristics and conidia of Fusarium species were morphologically assessed under a light microscope (Axio Imager Z2, ZEISS, Germany). One hundred thirty-seven isolates from 6 groups were identified as Fusarium spp. ${ }^{53,54}$.

PCR amplification of rDNA-ITS and EF-1 $\alpha$ sequences. All 137 obtained isolates were sub-cultured on PDA for 10 days at $25^{\circ} \mathrm{C}$ with 12 -h lighting. Approximately $20 \mathrm{mg}$ of mycelia of each isolate was then scraped from the PDA plates with a sterilized ladle, and mycelia were ground to a powder in liquid nitrogen with a mortar. DNA was extracted using the cetyl-trimethylammonium bromide (CTAB) method ${ }^{55}$, and DNA concentration and quality were estimated using a Thermo Scientific NanoDrop 2000 Spectrophotometer (Massachusetts, USA) with the default setting for DNA assays.

PCR amplification of $r D N A-I T S^{56}$ was performed with PCR primers ITS1 and ITS4 using the amplification conditions described by Schoch et al. ${ }^{57}$. Amplification of the Fusarium translation elongation factor $1 \alpha(E F 1-\alpha)$ gene was performed with the primer pair EF1 and EF2 using the amplification conditions described by O'Donnell et al. ${ }^{58}$. Molecular identification of Fusarium species was confirmed by PCR amplification using the primers ITS1 (TCCGTAGGTGAACCTGCGG) and ITS4 (GCTGCGTTCTTCATCGATGC) for the partial rDNA-ITS gene and the primers EF1-728F (CATCGAGAAGTTCGAGAAGG) and EF4-986R (TACTTGAAGGAACCCTTACC) for the partial EF1-a gene. PCR amplification was performed in a final volume of $25 \mu \mathrm{L}$ containing $12.5 \mu \mathrm{L}$ of $2 \times \mathrm{PCR}$ Master Mix (Vazyme, Nanjing, China), $0.5 \mu \mathrm{M}$ of each primer and $10 \mathrm{ng}$ of genomic DNA. The thermocycling conditions used for PCR amplification were as follows: $4 \mathrm{~min}$ at $94^{\circ} \mathrm{C}$ followed by 35 cycles of $45 \mathrm{~s}$ at $94{ }^{\circ} \mathrm{C}, 60 \mathrm{~s}$ at $53{ }^{\circ} \mathrm{C}$ (for EF1- $\alpha$ ) or $58^{\circ} \mathrm{C}$ (for $r D N A-I T S$ ), and $1 \mathrm{~min}$ at $72^{\circ} \mathrm{C}$, with a final extension at $72{ }^{\circ} \mathrm{C}$ for $10 \mathrm{~min}$. PCR products were detected by $1.5 \%$ agarose gel electrophoresis and then sequenced with an ABI-PRISM3730 automatic sequencer (Applied Biosystems, Foster, CA, USA) by Sangon Biotech Co., Ltd. (Shanghai, China). 
Phylogenetic analyses. Sequence analysis of the $r D N A-I T S$ region was first performed using BLAST at the National Center for Biotechnology Information (NCBI) database (http://www.ncbi.nlm.nih.gov). Then, the EF$1 \alpha$ sequences from Fusarium species were compared to those in the NCBI database using the DNA BLAST program and the FUSARIUM-ID database (http://isolate.fusariumdb.org/guide.php). The sequences were aligned using the software ClustalX $2^{59}$. Phylogenetic analyses were performed using MEGA5 software package with the default parameters ${ }^{60}$. The alignments were manually edited to delete trimmed regions and discard incomplete sequences. Phylogenetic trees for each genomic region and their tandem sequences were constructed using the neighbor-joining (NJ) approach ${ }^{61}$ with 1000 bootstrap repeats and the pairwise deletion option ${ }^{62}$. Bipolaris ory$z a e$ was used as an outgroup (GenBank accession no. KJ 939510).

Pathogenicity tests. Twenty-three isolates from eight identified species ( 3 representative isolates from each species, except for $F$. oxysporum with only 2 isolates) were assessed for pathogenicity on maize during the flowering period in 2016-2017. Subsequently, they were cultured on PDA medium at $25{ }^{\circ} \mathrm{C}$ under $12 \mathrm{~h}$ of ambient room lighting per day for 5 days. Thereafter, five mycelial plugs of each strain $(5 \mathrm{~mm}$ in diameter $)$ were transferred to $100 \mathrm{~mL}$ of CMC liquid medium and cultured for 3 days in a shaker incubator $\left(25^{\circ} \mathrm{C}, 160 \mathrm{rpm}\right)$. The conidial suspensions were then filtered and adjusted to a final concentration of $1 \times 10^{5} \mathrm{spores} / \mathrm{mL}$. Four maize cultivars (Chuandan 455, Chuandan 428, Zhenghong 6 and Ruiyu 16) were sown in field plots, with each field plot containing $23 \times 4$ lines and 40 plants per line. Then, a $2-\mathrm{mL}$ aliquot of a conidial suspension for each strain was injected into the first sheath above the ear leaf in 20 plants of each maize cultivar, and 20 control plants treated following the same procedure but were inoculated with sterile water ${ }^{63}$. Disease symptoms were assessed 25 days after inoculation, and disease severity was scored based on the average severity in 30 plants as described by Huang et al. ${ }^{49}$. Then, the disease index was calculated based on the average for each species. To confirm Koch's postulates, isolation from maize sheaths infected with one representative isolate of each Fusarium species was attempted. Subsequently, symptomatic maize sheath tissue was sectioned, and $0.5-\mathrm{cm}$ pieces were placed on PDA for reisolation under the same culture conditions.

Data analysis. Differences in the field survey, growth rate, conidial length and width and pathogenicity were analyzed using Statistical Package for Social Sciences (SPSS) (version 22.0 for Windows). Analysis of variance was performed using the general linear model, and means were compared using Duncan's New Multiple Range test with SPSS, with differences considered significant at $\mathrm{P} \leq 0.05$.

Received: 5 September 2020; Accepted: 19 January 2021

Published online: 02 February 2021

\section{References}

1. He, H. Y. et al. Regional gap in maize production, climate and resource utilization in China. Field Crop. Res. https://doi. org/10.1016/j.fcr.2020.107830 (2020).

2. Qi, J. Y., Yang, S. T., Xue, J. H. \& Liu, C. X. Response of carbon footprint of spring maize production to cultivation patterns in the Loess Plateau China. J. Clean. Prod. 187, 525-536 (2018).

3. Gao, Z. et al. Limits to maize productivity in the North China Plain: A comparison analysis for spring and summer maize. Field Crop. Res. 228, 39-47 (2018).

4. National Bureau of Statistics of China. Statistical communique of the People's Republic of China on national economic and social development in 2019. http://www.stats.gov.cn/tjsj/zxfb/202002/t20200228_1728913.html (2020).

5. Cui, A. M., Zhang, J. G., Zhang, H., Shan, H. \& Chen, W. Preliminary exploration on current situation and development of maize production in China. J. Agric. Sci. Tech. China. 22, 108-118 (2020).

6. Food and Agriculture Organization of the United Nations (FAO). http://www.fao.org/faostat/en/\#data (2018).

7. Yang, Q., Balint-Kurti, P. \& Xu, M. L. Quantitative disease resistance: Dissection and adoption in maize. Mol. Plant 10, 402-413 (2017).

8. Xu, X. D. et al. Corn sheath rot-a new disease found in China. Sci. Agric. Sin. 41, 3083-3087 (2018).

9. Li, P. P., Cao, Z. Y., Wang, K. \& Zhai, H. First report of Fusarium equiseti causing a sheath rot of corn in China. Plant Dis. 98, 998 (2014).

10. Jian, Q. J. et al. New insights into fumonisin production and virulence of Fusarium proliferatum underlying different carbon sources. Food Res. Int. 16, 397-407 (2019).

11. Zhai, H. Identification of the pathogen of corn sheath rot and pathogenic mechanism research. Agricultural University of Hebei, Pao Ting, China. https://kns.cnki.net/kcms/detail/detail.aspx?FileName=2010138751.nh\&DbName=CMFD2010 (2018).

12. Hu, L. et al. Study on biological characteristics of corn sheath rot causal agent. J. Maize Sci. 16, 131-134 (2008).

13. Wang, K. et al. Analysis of the correlation between diseased-degree of corn sheath rot and corn lodging and yield loss. J. Plant Prot. 42, 949-956 (2015).

14. Feng, G., Huang, C. L. \& Xing, J. F. The research progress in lodging resistance of maize. Crops 4, 12-14 (2008).

15. Liu, J. et al. Resistant evaluation and yield loss of common corn varieties to corn sheath rot. J. Maize Sci. 26, 29-36 (2018).

16. Yin, H. F. et al. The influence of aphids occurrence on corn sheath rot. J. Agric. Univ. Hebei 38, 86-91 (2015).

17. Xu, P. et al. The physiological mechanism of corn against Fusarium proliferatum infection. J. Plant Prot. 40, 261-265 (2013).

18. Li, Q. Q., Guo, M. K., Guo, C. \& Guo, J. G. Occurrence dynamics of maize diseases in Gansu Provence. Plant Prot. 40, 161-164 (2014).

19. Yuan, D. et al. Analysis of relationship among Fusarium pathogens of stalk, ear and sheath rots of maize Southwest China. J. Agric. Sci. 30, 1340-1345 (2017).

20. Sun, L. et al. First report of sheath rot of corn caused by Fusarium verticillioides in Northeast China. J. Plant Pathol. https://doi. org/10.1007/s42161-020-00582-7 (2020).

21. Wang, C. L. \& Cheng, Y. H. Identification and trichothecene genotypes of Fusarium graminearum species complex from wheat in Taiwan. Bot. Stud. 58, 4 (2017). 
22. Zhang, M. et al. Characterization of Fusarium root rot disease in grafted watermelon. Eur. J. Plant Pathol. https://doi.org/10.1007/ s10658-020-02013-w (2020).

23. Dugan, F. M., Hellier, B. C. \& Lupien, S. L. First report of Fusarium proliferatum causing rot of garlic bulbs in North America. Plant Pathol. 52, 426-426 (2003).

24. Chang, K. F. et al. First report of Fusarium proliferatum causing root rot in soybean (Glycinemax L.) in Canada. Crop Prot. 67, 52-58 (2015).

25. Gao, M. L., Luan, Y. S., Yu, H. N. \& Bao, Y. M. First report of tomato leaf spot caused by Fusarium proliferatum in China. Can. J. Plant Pathol. 38, 1-5 (2016).

26. Avasthi, S., Gautam, A. \& Bhadauria, R. First report of leaf spot disease of Aloe vera caused by Fusarium proliferatum in India. J. Plant. Protect. Res. 58, 109-114 (2018).

27. Ichikawa, K. \& Aoki, T. New leaf spot disease of Cymbidium species caused by Fusarium subglutinans and Fusarium proliferatum. J. Gen. Plant Pathol. 66, 213-218 (2000).

28. Zhou, X. et al. First report of leaf blight caused by Fusarium proliferatum on polygonatum cyrtonema in China. J. Plant Pathol. https ://doi.org/10.1007/s42161-020-00696-y (2020).

29. Sahouli, S. et al. Identification and characterization of Fusarium proliferatum on date palm in Algeria. J. Plant Pathol. 102, 1357$1358(2020)$.

30. Mondani, L., Chiusa, G., Pietri, A. \& Battilani, P. Monitoring the incidence of dry rot caused by Fusarium proliferatum in garlic at harvest and during storage. Postharvest Biol. Tech. https://doi.org/10.1016/j.postharvbio.2020.111407 (2020).

31. Kalman, B. et al. Isolation and identification of Fusarium spp., the causal agents of onion (Allium cepa) basal rot in Northeastern Israel. Biology 9, 69 (2020).

32. Naeem, M. et al. Characterization and pathogenicity of Fusarium species associated with soybean pods in maize/soybean strip intercropping. Pathogens 8, 245 (2019).

33. Li, P. P. Cell-wall degrading enzymes produced by Fusarium species and their pathogenicity to corn sheath. Agricultural University of Hebei, Pao Ting, China. https://kns.cnki.net/kcms/detail/detail.aspx?FileName=101233205-5.nh\&DbName=CMFD2012 (2018).

34. Qu, X. P. et al. Effects of the dinitroaniline fungicide fluazinam on Fusarium fujikuroi and rice. Pestic. Biochem. Physiol. 152, 98-105 (2018).

35. Choi, J. H. et al. Species composition of and fumonisin production by the Fusarium fujikuroi species complex isolated from Korean cereals. Int. J. Food Microbiol. 267, 62-69 (2018).

36. Hong, S. Y. et al. Functional analyses of two syntaxin-like SNARE genes, GzSYN1 and GzSYN2, in the ascomycete Gibberella zeae. Fungal Genet. Biol. 47, 364-372 (2010).

37. He, A. et al. Reprogrammed endophytic microbial community in maize stalk induced by Trichoderma asperellum biocontrol agent against Fusarium diseases and mycotoxin accumulation. Fungal Biol. 123(6), 448-455 (2019).

38. Birr, T., Hasler, M., Verreet, J. A. \& Klink, H. Composition and predominance of Fusarium species causing Fusarium Head Blight in winter wheat drain depending on cultivar susceptibility and meteorological factors. Microorganisms 8, 617 (2020).

39. Pfordt, A. et al. Occurrence, pathogenicity, and mycotoxin production of Fusarium temperatum in relation to other Fusarium species on maize in Germany. Pathogens 9, 864 (2020).

40. Colombo, E. M. et al. Investigating useful properties of four Streptomyces strains active against Fusarium graminearum growth and deoxynivalenol production on wheat grains by qPCR. Toxins 12, $560(2020)$.

41. Castanares, E., Dinolfo, M. I., Del Ponte, E. M. \& Pan, D. Species composition and genetic structure of Fusarium graminearum species complex populations affecting the main barley growing regions of South America. Plant Pathol. 65, 930-939 (2016).

42. Nerbass, F. R. et al. Field evaluation of maize for Gibberella ear rot resistance using silk channel and kernel inoculation with Fusarium meridionale. Trop. plant pathol. 40, 388-393 (2015).

43. Chang, X. et al. Maize/soybean relay strip intercropping reduces the occurrence of Fusarium root rot and changes the diversity of the pathogenic Fusarium species. Pathogens 9, 211 (2020).

44. Zhang, J. B. et al. Determination of the trichothecene mycotoxin chemotypes and associated geographical distribution and phylogenetic species of the Fusarium graminearum clade from china. Mycol. Res. 111, 967-975 (2007).

45. Fernández-Ortuño, D. et al. Simultaneous real-time PCR detection of Fusarium asiaticum, F. ussurianum and F. vorosii, representing the Asian clade of the F. graminearum species complex. Int. J. Food Microbiol. 166, 148-154 (2013).

46. Zhang, Z. et al. Geographic substructure of Fusarium asiaticum isolates collected from barley in China. Eur. J. Plant Pathol. 127, 239-248 (2010).

47. Kawakami, A. et al. Gibberella ear rot of corn caused by Fusarium asiaticum in Japan. J. Gen. Plant Pathol. 81, 324-327 (2015).

48. Chang, X. et al. Diversity of the seedborne fungi and pathogenicity of Fusarium species associated with intercropped soybean. Pathogens 9, 531 (2020).

49. Huang, T. S. et al. Identification and evaluation of maize germplasm for resistance to corn sheath blight (Rhizoctonia solani). J. Plant Genet. Resou. 6, 291-294 (2005).

50. Fang, Z. D. Methods of plant disease research (China agriculture press, Beijing, 1998).

51. Gong, G. S. et al. A simple method for single fungal spore isolation. J. Maize Sci. 18(126-127), 134 (2010).

52. Chang, X. et al. Identification of Fusarium species associated with soybean root rot in Sichuan Province China. Eur. J. Plant Pathol. 151, 563-577 (2018)

53. Gerlach, W. \& Nirenberg, H. The genus Fusarium-a pictorial atlas. Mitt. Biol. Bundesanst. Land-u. Forstwirtsch. Berlin-Dahlem. 209, 1-406 (1982).

54. Leslie, J. F. \& Summerell, B. A. The Fusarium Laboratory Manual. Blackwell Professional, Ames, Iowa. http://download.xuebalib. com/xuebalib.com.52882.pdf (2006).

55. Pipe, N. D., Azcoitia, V. \& Shaw, D. S. Self-fertility in phytophthora infestans: Heterokaryons segregate several phenotypes. Mycol. Res. 104, 676-680 (2000).

56. White, T. J., Bruns, T., Lee, S. \& Taylor, J. 38-amplification and direct sequencing of fungal ribosomal RNA genes for phylogenetics. Editor(s): Michael A. Innis, David H. Gelfand, John J. Sninsky, Thomas J. White. PCR Protocols 315-322 http://linkinghub.elsev ier.com/retrieve/pii/B9780123721808500421 (1990).

57. Schoch, C. L. et al. Nuclear ribosomal internal transcribed spacer (ITS) region as a universal DNA barcode marker for Fungi. PNAS 109, 6241-6246 (2012).

58. O’Donnell, K. \& Cigelnik, E. Two divergent intragenomic RDNA ITS2 types within a monophyletic lineage of the fungus Fusariumare nonorthologous. Mol. Phylogenet. Evol. 7, 103-116 (1997).

59. Larkin, M. A. et al. Clustal W and clustal X version 2.0. Bioinformatics 23, 2947-2948 (2007).

60. Tamura, K. et al. MEGA5: Molecular evolutionary genetics analysis using maximum likelihood, evolutionary distance, and maximum parsimony methods. Mol. Boil. Evol. 28, 2731-2739 (2011).

61. Saitou, N. N. M. \& Nei, M. The neighbour-joining method: A new method for reconstructing phylogenetic trees. Mol. Biol. Evol. 4, 406-425 (1987).

62. Ortu, G., Bertetti, D., Gullino, M. \& Garibaldi, A. New formae speciales of Fusarium oxysporum on ornamental plants. Acta Hortic. 1044, 89-92 (2014).

63. Li, W. J., He, P. \& Jin, J. Y. Effect of potassium on ultrastructure of maize stalk pith and young root and their relation to stalk rot resistance. Agr. Sci. China 9, 1467-1474 (2010). 


\section{Author contributions}

Conceptualization, W.W., W.B. and G.G.; Data curation, S.X.; Formal analysis, S.X., Q.X. and Z.C.; Funding acquisition, G.G.; Investigation, W.W. and W.B.; Methodology, W.W., W.B., S.X. and G.G.; Project administration, G.G.; Resources, G.G.; Software, W.W. and Q.X.; Supervision, C.X. and G.G.; Validation, W.W. and G.G.; Visualization, W.W. and W.B.; Writing-original draft, W.W.; Writing—review \& editing, C.X., M.I.K. and G.G.

\section{Funding}

This work was funded by Sichuan Maize Innovational Team of Industry Technology System of Modern Agriculture (Grant no. sccxtd-2020-02).

\section{Competing interests}

The authors declare no competing interests.

\section{Additional information}

Supplementary Information The online version contains supplementary material available at https://doi. org/10.1038/s41598-021-82463-2.

Correspondence and requests for materials should be addressed to G.G.

Reprints and permissions information is available at www.nature.com/reprints.

Publisher's note Springer Nature remains neutral with regard to jurisdictional claims in published maps and institutional affiliations.

Open Access This article is licensed under a Creative Commons Attribution 4.0 International License, which permits use, sharing, adaptation, distribution and reproduction in any medium or format, as long as you give appropriate credit to the original author(s) and the source, provide a link to the Creative Commons licence, and indicate if changes were made. The images or other third party material in this article are included in the article's Creative Commons licence, unless indicated otherwise in a credit line to the material. If material is not included in the article's Creative Commons licence and your intended use is not permitted by statutory regulation or exceeds the permitted use, you will need to obtain permission directly from the copyright holder. To view a copy of this licence, visit http://creativecommons.org/licenses/by/4.0/.

(C) The Author(s) 2021 